\title{
ESTUDO DA BIODEGRADAÇÃO DE HIDROCARBONETOS POLICÍCLICOS AROMÁTICOS (HPA) APÓS ATUAÇÃO DE CONSÓRCIO FÚNGICO EM MEIO MINERAL SUPLEMENTADO COM PETRÓLEO BRUTO
}

\author{
S. D. da ROCHA ${ }^{1}$, L. M. de CASTRO ${ }^{1}$, E. P. ELIAS $^{1,2}$, T. C. S. de OLIVEIRA ${ }^{1}$ \\ ${ }^{1}$ Universidade Federal do Amazonas, Departamento de Química \\ ${ }^{2}$ Instituto Federal do Amazonas, Departamento de Química \\ E-mail para contato: sissarocha26@ gmail.com
}

\begin{abstract}
RESUMO - O interesse pelo estudo da contaminação por hidrocarbonetos policíclicos aromáticos e seus derivados reside no fato de que a maioria deles são potencialmente carcinogênicos e mutagênicos. Nesse sentido, destacam-se os processos de biorremediação, que tem como principal finalidade controlar as taxas de contaminação, com baixos custos e impactos mínimos aos ecossistemas. O presente estudo destaca a importância dos fungos associados à macrófita aquática Eichhornia crassipes Mart. Solms coletada em áreas contaminadas por hidrocarbonetos de petróleo. Foi produzido um consórcio com os fungos mais eficientes (Phoma herbarum, Fusarium moliniforme, e Penicillium citrinum), utilizando as técnicas de bioaumentação e bioestimulação. Para avaliar o comportamento da degradação do petróleo pelos fungos foi verificada a produção de compostos HPA a partir da realização de métodos analíticos, como: extração líquido-líquido do meio mineral suplementado com petróleo bruto na pesença do consórcio, em seguida realizou-se o fracionamento e a determinação da concentração individual dos HPA por Cromatografia Gasosa acoplada à Espectrometria de Massas. De acordo com os tempos de observação: 24 horas, 7 e 14 dias, o meio ácido sem adição de nutrientes apresentou-se mais eficiente na degradação dos HPA. Com a realização deste estudo acredita-se ser possível obter bioprodutos para remediação de áreas impactadas com petróleo.
\end{abstract}

\section{INTRODUÇÃO}

A poluição ambiental causada pela liberação de hidrocarbonetos, decorrente das atividades industriais e dos derramamentos acidentais de petróleo e seus derivados apresentam grandes riscos aos ecossistemas aquáticos e terrestres e as técnicas para sua remediação têm recebido destaque nas últimas décadas (Tonini et al., 2010). Os tratamentos tradicionais, tais como barreiras flutuantes de contenção e recolhimento, adsorção de materiais naturais ou sintéticos não visam à degradação do petróleo (Andrade et al., 2010). Nesse contexto destacam-se os processos de biorremediação, que utilizam microrganismos para minimizar ou remover poluentes do ambiente.

De acordo com Oliveira (2006) a biorremediação vem sendo bastante fundamentada na recuperação de ambientes impactados por hidrocarbonetos de petróleo por utilizar o potencial metabólico de certos microrganismos e diminuir o caráter tóxico de determinados compostos. No processo de biorremediação há exploração da diversidade genética e do potencial metabólico dos microrganismos para que ocorra a transformação de contaminantes em produtos finais menos tóxicos, os quais são integrados nos ciclos biogeoquímicos naturais (Alexander, 1994). 
Marín et al. (2006) destacam os dois enfoques da biorremediação: bioaumento e bioestímulo, que consistem na adição de microrganismos degradadores de hidrocarbonetos ou de biossurfactantes e estimulação do crescimento microbiano no local contaminado pela adição de nutrientes, respectivamente. A eficiência do processo de biorremediação pode ser determinada pela avaliação de hidrocarbonetos saturados e hidrocarbonetos policíclicos aromáticos (HPA), pois são marcadores moleculares indicadores de poluição e de processos de degradação de petróleo e seus derivados no ambiente (Peters et al., 2005). Dentre os HPA, destacam-se os 16 HPA que são considerados poluentes de alta prioridade ambiental pela United States Environmental Protection Agencia (USEPA) devido ao seu potencial carcinogênico e mutagênico (US-EPA, 2007).

Este trabalho apresenta a proposta de ação biorremediadora de microrganismos associados à macrófita aquática Eicchornia crassipes Mart. Solms, presentes em áreas aquáticas sob influência de hidrocarbonetos provenientes de resíduos de petróleo e seus derivados. A obtenção do consórcio fúngico por meio de técnicas de bioaumento e bioestímulo proporciona um avanço nas pesquisas sobre biorremediação. O presente trabalho está inserido no escopo do projeto da Rede CTPetro Amazônia: Tecnologias para a recuperação de ecossistemas e conservação da biodiversidade na Amazônia Brasileira" que visa desenvolver técnicas limpas e eficazes para minimização de poluentes do meio ambiente buscando a preservação da biodiversidade dos ecossistemas aquáticos e terrestres.

\section{METODOLOGIA}

\subsection{Amostragem}

A produção do consórcio de fungos envolve linhagens selecionadas de fungos isolados em meio seletivo a partir da macrófita Eicchornia crassipes Mart. Solms (Figura 1.A-B) que foi coletada no igarapé da Guarita (S0308'46.3" e O59 57'24,4"), área que recebe a saída do efluente da REMAN - refinaria da Petrobrás/Manaus-AM. Estas linhagens foram identificadas como Phoma herbarum, Fusarium moliniforme, e Penicillium citrinum. Foram recolhidos indivíduos em triplicata, contendo folhas, caules, bulbos e raízes, Após a coleta, as amostras foram acondicionadas em sacos plásticos de polietileno transparentes e transportadas para o laboratório.
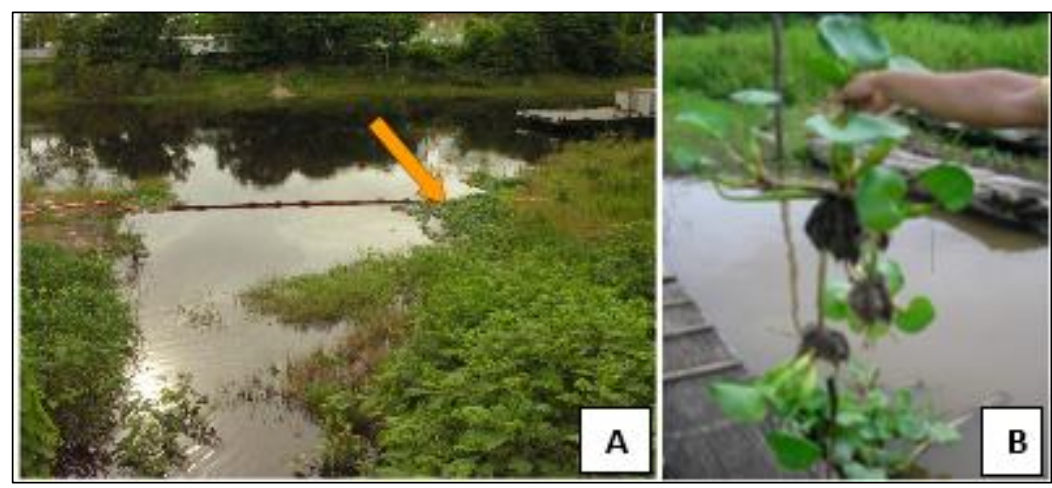

Figura 1 - A: Saída dos efluentes da Refinaria Isaac Sabá - Manaus/AM. B: Amostra da macrófita aquática Eichhornia crassipes Mart. Solms. 


\subsection{Isolamento dos Fungos}

Foi realizado o isolamento de fungos epifíticos e endofíticos segundo a metodologia descrita por Pereira (1993). Após o crescimento e esporulação dos fungos isolados foram geradas culturas monospóricas a fim de se obter uma nova colônia a partir de um único conídio de acordo com o protocolo desenvolvido por Azevedo e Costa (1973).

\subsection{Reativação dos Fungos e Produção de Consórcio Microbiano}

Foram utilizadas três linhagens de fungos isolados da macrófita aquática Eichhornia crassipes Mart. Solms, identificados como: Fusarium moniliforme, Penicillium citrinum e Phoma herbarum. A partir destas linhagens foi produzido um consórcio visando avaliar a capacidade do mesmo em degradar petróleo em experimento contendo meio BH (Buchnell Haas) em uma concentração de 5 mL. $\mathrm{L}^{-1}$.

Os fungos foram dispostos para crescer em placa de Petri contendo meio de cultura BDA (Batata, Dextrose e Agar) com petróleo no período de 7 (sete) dias. Após crescimento fúngico, foi produzido o consórcio, no qual com auxílio de uma seringa estéril de $3 \mathrm{~mL}$ (sem o bico), foi retirado um bloco de tamanho padrão de cada um dos fungos e introduzidos em Erlenmeyer de 125 mL estéreis, contendo $20 \mathrm{~mL}$ de meio BH conforme Oliveira (2001). Os frascos foram agitados por um minuto em vórtex, em seguida foram acrescentados $30 \mu \mathrm{L}$ de petróleo bruto (cedido pela Refinaria de Manaus - REMAN - Petrobras, originário do Pólo de Produção Urucu) e reservados para realização dos experimentos de bioaumento e bioestímulo.

\subsection{Experimentos de Bioaumento e Bioestímulo}

Os experimentos foram conduzidos em erlenmeyers de $125 \mathrm{~mL}$ e em cada um foram adicionados $20 \mathrm{~mL}$ de meio $\mathrm{BH}$ (com pH ajustado para 5,5 e 8) acrescido com $30 \mu \mathrm{L}$ de petróleo, adição ou não do consórcio fúngico e com fonte adicional ou não de nutrientes. Para cada Erlenmeyer com adição de nutrientes foram adicionados $0,4 \mathrm{~g}$ de glicose, nitrato de amônio e fosfato monopotássico. Os frascos foram colocados em incubadora shaker a temperatura de $28^{\circ} \mathrm{C}$ a $240 \mathrm{rpm}$, sendo retirados para extração dos HPA nos tempos de 24 horas, 7 e 14 dias. Os controles foram considerados os erlenmeyers sem adição do consórcio microbiano. O processo de extração líquido-líquido visando à obtenção da fase orgânica da amostra foi realizado conforme método EPA 3510C (US-EPA, 1996). Foram adicionados nas amostras $100 \mu \mathrm{L}$ do mix de padrões de recuperação certificados fenantreno D10 e perileno D12, à concentração de $50 \mu \mathrm{g} \cdot \mathrm{mL}^{-1}$. Após a adição padrão as amostras foram submetidas à extração com uma mistura de $40 \mathrm{~mL}$ de solventes diclorometano e hexano (UV/HPLC) na proporção 1:1.

Os processos de limpeza e fracionamento do extrato foram realizados por cromatografia líquida utilizando sílica gel ativada como fase estacionária, $1 \mathrm{~g}$ de alumina 5\% desativada (p/v) para reter possíveis impurezas presentes na amostra. A fração alifática (F1) foi eluída com hexano e a fração aromática (F2) eluída com a mistura 1:1 hexano e diclorometano. Em seguida procedeu-se a concentração das duas frações em evaporador rotativo para redução do volume até $1 \mathrm{~mL}$. A F1 foi reservada para posterior análise. A determinação da concentração final dos 16 HPA em CG/EM, onde os compostos foram identificados por análise com padrões certificados e indicação de seus tempos de retenção, conforme o método EPA 8270D (US-EPA, 2007). Todos os experimentos descritos acima foram realizados com o consórcio dos fungos em triplicatas, a fim de verificar melhor eficiência no processo de degradação de hidrocarbonetos. 
A tentativa de otimização das condições de degradação de HPA pode ser mensurada pelo uso da técnica de experimentos fatoriais completos. Segundo Parvez et al.(2008), experimentos fatoriais $2^{\mathrm{n}}$ revelam os efeitos principais de cada fator individualmente como também das várias interações entre os fatores que influenciam na variável resposta (efeito). Entre as vantagens deste tipo de experimento está a redução do número de ensaios necessários para avaliação das melhores condições para um determinado planejamento. Neste estudo, foi realizado um experimento do tipo $2^{3}$ e o os detalhes são listados na Tabela 1. A análise estatística dos dados foi efetuada com o auxílio do software Action 2.4. Os efeitos de interação foram estimados por meio de análise multifatorial ANOVA.

Tabela 1 - Planejamento do experimento fatorial do tipo $2^{3}$

\section{Variável resposta}

Fatores/Níveis

Número de réplicas

Número de corridas
\% Degradação

Tempo / $-1=24 \mathrm{~h} ;+1=7$ dias

$\mathrm{pH} /-1$ = Ácido; +1 = Básico

Condição $/-1=$ sem nutrientes; $+1=$ com nutrientes

3

24

\section{RESULTADOS E DISCUSSÃO}

A intensidade de biodegradação dos HPA é influenciada por diversos fatores, como: disponibilidade de nutrientes, oxigênio, $\mathrm{pH}$, composição, concentração, entre outros (MARGESIN \& SHINNER, 2001). A mineralização dos hidrocarbonetos é favorecida em valores de $\mathrm{pH}$ próximos à neutralidade. Contudo, existem relatos de processos de biodegradação em solos ácidos de florestas tropicais com pH variando de 4,0 a 6,0 (AMADI et al., 1996). De acordo com Alexander (1994), muitas espécies de fungos desenvolvem-se melhor em $\mathrm{pH}$ ácido.

Analisando os valores médios de percentagem de degradação (Figura 2), expostos por meio de um gráfico em cubo, verifica-se que a melhor configuração ocorre em meio ácido sem adição de nutrientes após 7 dias. Entretanto, a interação entre os fatores pode ser significativa, necessitando-se de uma avaliação mais detalhada dessa hipótese.

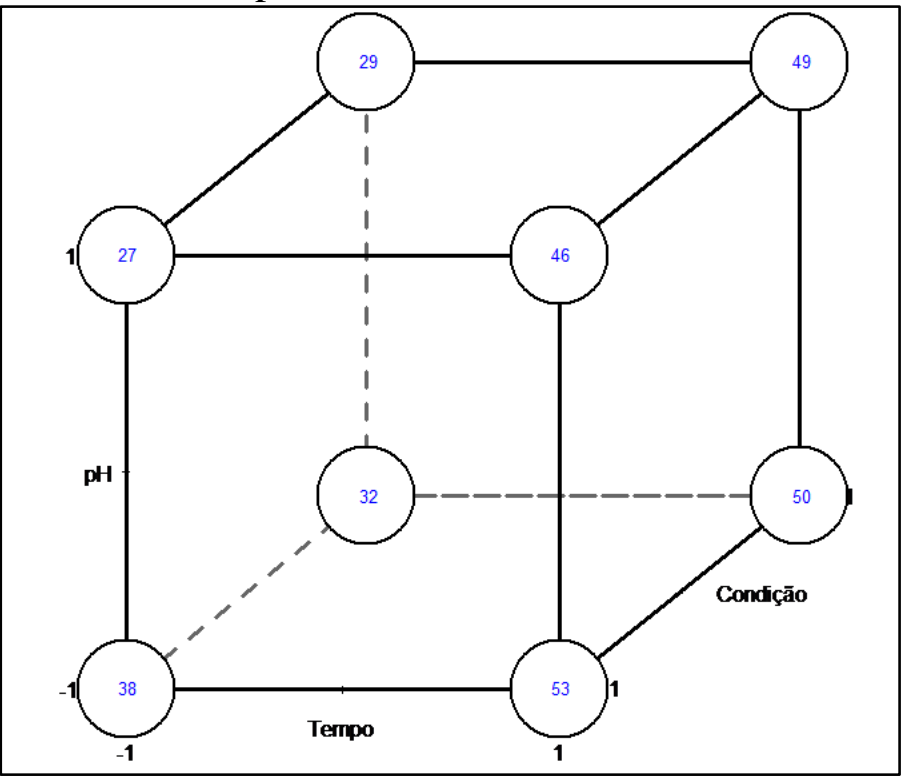

Figura 2 - Médias das percentagens de degradação dos HPA 
O percentual de recuperação do mix de padrões de referência fenantreno D10 e perileno D12 adicionado antes do método de extração liquido-líquido variou de 55 a 90\%. Na Figura 3, o gráfico mostra que não ocorre interação entre os fatores tempo e pH (linhas paralelas). Já os fatores pH e condição apresentam uma interação significativa representando que a adição ou não de nutrientes é dependente do pH influenciando na degradação de HPA. A distância curta entre as linhas dos fatores condição e tempo mostra que este primeiro pouco influi na variável resposta.

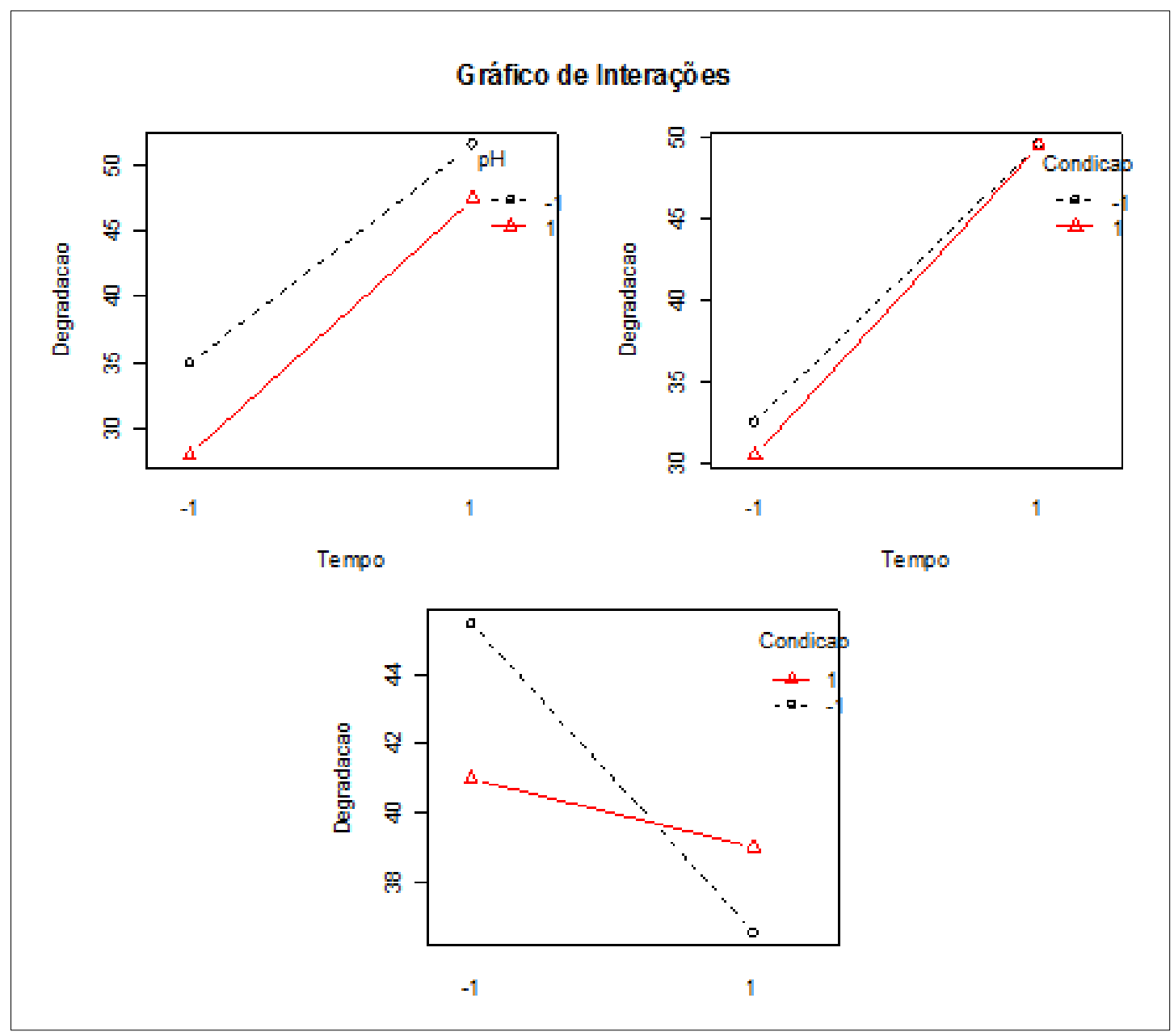

Figura 3 - Interações entre os fatores tempo, pH e condição

A importância de se gerar uma tabela ANOVA (Tabela 2) se deve a possibilidade de quantificar a parcela de variabilidade total de cada fator e a interação entre estes. Avaliando a Tabela 2 verifica-se que apenas o fator tempo se mostrou significante ( $\mathrm{P}$-valor $<0,05)$, porém os fatores $\mathrm{pH}$ e condição se mostraram não-significativos.

O gráfico de interações e a tabela ANOVA permitiram averiguar que apenas o fator tempo mostrou-se significativo $\left(\mathrm{F}_{\text {crítico }}=82,285\right)$, logo, a configuração que resulta em uma melhor degradação de HPA é: Tempo: 7 dias (+1), pH: ácido (-1) e Condição: sem adição de nutrientes ($1)$. 
Tabela 2 - Tabela de análise dos efeitos de interação ANOVA

\begin{tabular}{cccccc}
\hline Fatores & G.L. & $\begin{array}{c}\text { Soma de } \\
\text { Quadrados }\end{array}$ & $\begin{array}{c}\text { Tuabela da Anova } \\
\text { Médio }\end{array}$ & Estatística F & P-valor \\
Tempo & 1 & 648 & 648 & 82,28571429 & 0,000818674 \\
pH & 1 & 60,5 & 60,5 & 7,682539683 & 0,050241421 \\
Condição & 1 & 2 & 2 & 0,253968254 & 0,640785365 \\
Resíduos & 4 & 31,5 & 7,875 & & \\
\hline
\end{tabular}

Foi verificado que o fator tempo exerce bastante influência nos processos de degradação, visto que em até 7 dias de experimento houve um decaimento considerável do somatório total do 16 HPA presentes no meio mineral suplementado com petróleo bruto. Fato não observado satisfatoriamente após 14 dias, pois houve pouca variação na concentração dos hidrocarbonetos. De acordo com Jacques (2007), dependendo das condições, esse tempo pode variar, pois é importante considerar que a bioestimulação deve ser precedida de criteriosa avaliação, visando determinar os nutrientes e as doses que necessitam ser adicionadas.

Os resultados evidenciam que na ausência do carbono proveniente da degradação de matéria orgânica, os microrganismos com enzimas para a degradação de hidrocarbonetos se desenvolveram aproveitando os compostos do petróleo como fonte de carbono e energia, promovendo assim a mineralização desses compostos. Castiglioni et al.(2009), ao avaliarem a produção de biossurfactantes por fungos filamentosos, encontraram valores que comprovam que os experimentos sem fonte adicional de carbono foram os que apresentaram os melhores resultados.

\section{CONSIDERAÇÕES FINAIS}

Após a análise cromatográfica foram obtidos o somatório das concentrações dos 16 HPA presentes nas amostras e com auxílio de uma ferramenta estatística foi possível verificar que as amostras com pH ajustado para ácido e sem adição de nutrientes apresentaram uma diminuição acentuada na concentração dos hidrocarbonetos presentes. Os resultados evidenciaram que os fungos: Phoma herbarum, Fusarium moliniforme, e Penicillium citrinum possuem potencial para degradar hidrocarbonetos de petróleo, pois apresentaram uma alta taxa de biodegradação dos HPA total presentes no óleo bruto ao final de 7 dias de experimento. Assim, possuem características promissoras para o emprego em biorremediação. A análise via ANOVA permitiu com sucesso estipular as melhores condições a serem aplicadas in vitro de forma a se otimizar os processos de degradação de hidrocarbonetos, neste caso de HPA.

\section{REFERÊNCIAS BIBLIOGRÁFICAS} 1994.

ALEXANDER, M. Biodegradation and bioremediation. San Diego, Academic Press Inc.,

ANDRADE, J. de A., AUGUSTO, F. \& JARDIM, Isabel C. S. F. Biorremediação de solos contaminados por petróleo e seus derivados. Eclética Quím., São Paulo, 35 - 3: 17 - 43, 2010. 
APHA - American Public Health Association; American Water Work Associatin - AWWA; Water Pollution Control Federation - WPCF. Standard Methods of the Experimination of Water and Wasterwater. ed. New York, p.1268, 2012.

AZEVEDO, J.L. e COSTA, S.O.P. Exercícios práticos de Genética. São Paulo, Editora Nacional, 288p, 1973.

CASTIGLIONI, Gabriel L.; BERTOLIN, Telma E.; COSTA, Jorge Alberto V. Produção de biossurfactante por Aspergillus fumigatus utilizando resíduos agroindustriais como substrato. Quím. Nov., v. 32, no. 2, p.292-295, 2009.

JACQUES, Rodrigo J. S.; BENTO, Fátima M. \& CAMARGO, Flávio A. O., ANTONIOLLI, Zaida Inês. Biodegradação de hidrocarbonetos aromáticos policíclicos. Ciência e Nat., UFSM, v. 29 (1), p. 7 - 24, 2007.

MARGESIN, R. SCHINNER, F. Chronic effects of oil spill on soil properties and microflora of a rainforest ecosystem in Nigeria: Water Air Soil Pollut., v.86(1-4), p.1-11,. 1996.

MARÍN, J.A.; MORENO, J.L.; HERNÁNDEZ, T. \& GARCÍA, C. Bioremediation by composting of heavy oil refinery sludge in semiarid conditions. Biodegrad., 17:251-261, 2006.

OLIVEIRA, Fernando J. S. O. Biorremediação de solo arenoso contaminado por óleo cru. Dissertação de mestrado. Universidade Federal do Rio de Janeiro, 2001.

OLIVEIRA, V. M., MANFIO, G.P. Molecular approaches for the screening of novel enzymes. In: Jean-Louis Reymond. (Ed.). Enzyme Assays: High-throughput screening, genetic selection and fingerprinting. p. 221-238, 2006.

PEREIRA, J. O. Fungos endófitos de hospedeiros tropicais Stylosanthes guianensis e Musa cavendeis. Tese de Doutorado: Piracicaba, 1993.

PARVEZ, S.; VENKATARAMAN, C.; MUKHERJI, S.; Toxicity assessment of organic contaminants: Evaluation of mixture effects in model industrial mixtures using $2^{\mathrm{n}}$ full factorial design. Chemosph.; Mumbai, v. 73, p. 1049-1055, 2008.

PETERS, K. E., WALTERS, C. C. \& MOLDOWAN, J. M.; The Biomarker Guide: Biomarkers and Isotopes in the Environment and Human History. Cambridge University Press, 2005, $471 \mathrm{p}$.

TONINI, R. M. C. W.; REZENDE, C. E. de; GRATIVOL, A. D. Degradação e Biorremediação de Compostos do Petróleo por Bactérias: Revisão. Oecologia Aust., 14(4): 10271035, 2010.

US-EPA Environmental Protection Agency. Method 3510 C. Separatory funnel liquid-liquid extraction. 1996.

US-EPA Environmental Protection Agency. Method 8270 D. Semivolatile organic compounds by gas chromatography/ Mass spectrometry. 2007. 